\title{
On the measurement of air permeability
}

\author{
P. H. Groenevelt ${ }^{1}$ and G. G. Lemoine ${ }^{2}$ \\ ${ }^{1}$ Department of Land Resource Science, University of Guelph, Guelph, Ontario, \\ Canada N1G 2W1 \\ ${ }^{2}$ Department of Soil Science and Plant Nutrition, Wageningen Agricultural Uni- \\ versity, P.O. Box 8005, NL 6700 EC Wageningen, Netherlands
}

Received 11 May 1987; accepted 30 June 1987

Key words: intrinsic permeability, ideal gas law, water potential

\begin{abstract}
Air permeability values are used to assess the state of aeration, soil structural stability, structural degradation and compaction. A simple experimental procedure, with a constant-speed motor, a syringe and simple pressure sensors, is discussed.

At steady-state air flow through a soil sample the air permeability coefficient can be derived directly from the observations with Kirkham's equation. For transient conditions an equation is presented, based on a combination of Kirkham's equation and the ideal gas law, from which the air permeability coefficient can be deduced by trial and error.

The importance of the soil water potential, in relation to the measurement of air permeability, is discussed.

Complications arising from the 'non-ideal' behaviour of the pressure sensor are also discussed.
\end{abstract}

\section{Introduction}

By measuring the air permeability of a soil, or any other porous material, one can obtain useful information about the geometry of its air-filled pores. Combined with information from the moisture retention function and the penetrability characteristic, a fair assessment can be made of the structural quality, the state of compaction and root penetrability, as well as possible aeration problems.

Air permeability compared to water permeability has been used as an index of structural stability of the soil (Buehrer, 1932; Reeve, 1953; Janse \& Bolt, 1960). Combined evaluation of air permeability and penetrability may provide a measure of the structural degradation of soil due to intensive cultivation (Ball, 1981b; Groenevelt et al., 1984). In addition, the measurement of the air permeability is successfully used as a workability test for arable land (Perdok \& Hendrikse, 1982). Air permeability is also used in fundamental research concerning physical prop- 
erties of porous materials (Marshall, 1958; Ball, 1981a). Standard laboratory procedures are described by Corey (1986).

\section{Instrumentation}

In an attempt to create a compact, easy-to-handle instrument the 'constant-flux permeameter' was developed. The basic principle is the imposition of a constant air flux and the measurement of the resulting pressure difference across a soil sample.

A piston, moving in a syringe at constant velocity, 'builds up' a pressure difference across an attached soil core, until the pressure difference becomes constant, at which time the mass flux of air through the soil core also becomes constant. As in a method described by Ball et al. (1981), both the flux and the pressure difference can be precisely controlled for constancy.

The present set-up allows for the selection of a flux ranging from $3 \times 10^{-9}$ to $3 \times$ $10^{-5} \mathrm{~m}^{3} \mathrm{~s}^{-1}$. The possibility to select the lowest 'workable' flux is important when attempting to avoid complications due to air turbulence, water displacement and resistance to air flow in the tubing.

The instrument consists of a pump (Saga Instruments model 355) that drives the piston in a syringe at a constant speed. A set of three syringes (Becton-Dickinson disposable syringes) with graded volumes of 35,60 and $140 \mathrm{~cm}^{3}$, together with the two switches on the pump, provides the range of fluxes mentioned above. The inner walls of the syringes are greased with vaseline to secure smooth movement and to prevent air leaks.

The air pressure at the air-entry side of the soil sample is measured with a magnehelic pressure gauge (Dwyer Instruments Inc.) or with a water manometer (Fig. 1).

The soil sample is clamped in a holder which contains an O-ring.

The set-up is checked for air leaks by running the equipment with an impermeable sample (e.g. a rubber stopper) or by closing the air outlet. After stopping the pump the air pressure should stay constant.

The outflow side of the soil sample is left open to the atmosphere. The recorded pressures are above atmospheric pressure.

\section{Water potentials}

The energy level of the water in the soil has a dominant effect on the air permeability. From a point of view of physics one may argue that it is the water content, determining the air-filled pore space, which is most directly dictating the air permeability. However, from a practical point of view, it is often preferable to choose the energy level as the determining parameter. For instance, for comparing air permeabilities of a particular soil in field plots under different tillage treatments, it is probably more accurate to assume that the water potentials are equal rather than the water contents. Therefore, we perform air permeability measurements at a specified water potential.

There are three common ways to express water potentials, viz as energy per unit mass, per unit volume or per unit weight. In soil physics a preference exists for the 


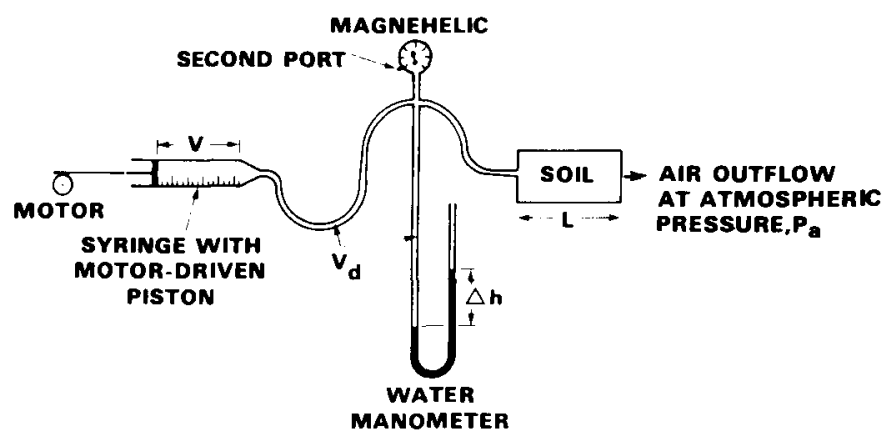

Fig. 1. Instrumentation for air-permeability measurements. $V$ is the volume in the syringe and $V_{\mathrm{d}}$ is the 'dead' volume.

first choice (cf. e.g. Bolt \& Miller, 1958). That branch of science is in need of a name for the derived SI unit $\mathrm{J} \mathrm{kg}^{-1}$. We now suggest the name Bolt with the symbol Bo. For a fluid with a density of $1 \mathrm{Mg} \mathrm{m}^{-3}, 1 \mathrm{Bo}$ is equivalent to $1 \mathrm{kPa}$. Further, $1 \mathrm{Bo}$ is equivalent to $0.1 \mathrm{~m} \mathrm{H}_{2} \mathrm{O}$ height if one approximates the acceleration in the gravity field by $10 \mathrm{~m} \mathrm{~s}^{-2}$.

In our experiments concerning the 'rootability' of soils (Groenevelt et al., 1984), all soil samples were equilibrated at $-5 \mathrm{Bo}$, so that the equivalent diameter $(d)$ of the air-filled pores was $\geqslant 60 \mu \mathrm{m}(60 \mu \mathrm{m}$ being the approximate diameter of a growing maize root), according to

$$
d(\mathrm{~m}) \simeq-3 \times 10^{-4} / \psi(\mathrm{Bo})
$$

\section{Calculation of the air permeability coefficient}

When steady-state air flow is established and both the flux and the pressure drop across the soil sample are constant, the air permeability coefficient can be calculated from the equation derived by Kirkham (1946):

$$
Q_{\mathrm{i}} / A=k\left(P_{\mathrm{i}}^{2}-P_{\mathrm{a}}^{2}\right) /\left(2 \mu L P_{\mathrm{i}}\right)
$$

where

$Q_{\mathrm{i}}=$ the volume of air, measured at the high-pressure or 'inlet' side of the soil sample, passing into the soil sample per unit time $\left(\mathrm{m}^{3} \mathrm{~s}^{-1}\right)$

$A=$ the cross-sectional area of the soil sample $\left(\mathrm{m}^{2}\right)$

$k=$ the intrinsic air permeability $\left(\mathrm{m}^{2}\right)$

$P_{\mathrm{i}}=$ the air pressure at the high-pressure or 'inlet' side of the soil sample $(\mathrm{Pa})$

$P_{\mathrm{a}}=$ the air pressure at the outlet side, kept at atmospheric pressure (Pa)

$\mu=$ the viscosity of air $\left(\mathrm{N} \mathrm{m}^{-2} \mathrm{~s}\right)$

$L=$ the length of the soil sample in the flow direction (m)

In Eq. 2 one finds $P_{\mathrm{i}}$ in the denominator because $Q$ is measured at the air 'inlet' side. The equivalent form of Eq. 2, with pressure heads, is: 


$$
Q_{\mathrm{i}} / A=K\left(h_{\mathrm{i}}^{2}-h_{\mathrm{a}}^{2}\right) /\left(2 L h_{\mathrm{i}}\right)
$$

where

$K=\varrho_{\mathrm{w}} g k / \mu\left(\mathrm{m} \mathrm{s}^{-1}\right)$

$h \quad=P /\left(\varrho_{\mathrm{w}} g\right)=$ pressure head $(\mathrm{m})$

$\varrho_{\mathrm{w}}=$ the density of water $\left(\mathrm{kg} \mathrm{m}^{-3}\right)$

$g=$ the acceleration in the gravity field $\left(\mathrm{m} \mathrm{s}^{-2}\right)$

Eq. 2 may be written as

$$
Q_{\mathrm{i}} / A=k(\mu L)^{-1} \Delta P\left(1-\Delta P / 2 P_{\mathrm{i}}\right)
$$

where $\Delta P=P_{\mathrm{i}}-P_{\mathrm{a}}$.

Similarly, Eq. 3 may be written as

$$
Q_{\mathrm{i}} / A=K L^{-1} \Delta h\left(1-\Delta h / 2 h_{\mathrm{i}}\right)
$$

where $\Delta h=h_{\mathrm{i}}-h_{\mathrm{a}}$.

For experiments during which $\Delta h$ does not rise above $0.2 \mathrm{~m} \mathrm{H}_{2} \mathrm{O}$, the terms in parenthesis in Eqs. 4 and 5 may be deleted without loosing more than $1 \%$ accuracy.

The above procedure is simple and straight forward. However, it is not seldom that, with the available equipment, steady-state air flow cannot be established due to limitations of either the syringe or the pressure sensor. Then, the air permeability coefficient must be calculated from observations during the transient state.

During the transient state air flow process two extensive and one intensive variable in the ideal gas law are time functions. They are the volume, the amount of substance and the pressure. This situation differs from that discussed by Kirkham (1946), in which case the volume was constant, and only the amount of substance and the pressure were time functions.

For the present set-up the ideal gas law may be written as:

$$
P\left(V+V_{\mathrm{d}}\right)=M R T
$$

where

$P=$ the air pressure at the inlet side of the soil sample, $=P_{\mathrm{i}}(\mathrm{Pa})$

$V=$ the calibrated volume of air in the syringe ahead of the piston $\left(\mathrm{m}^{3}\right)$

$V_{\mathrm{d}}=$ the 'dead' volume between the syringe and the soil sample (tubes and connecting spaces) $\left(\mathrm{m}^{3}\right)$

$M=$ the amount of air in the space $\left(V+V_{\mathrm{d}}\right)(\mathrm{mol})$

$R=$ the universal gas constant $\left(\mathrm{J} \mathrm{mol}^{-1} \mathrm{~K}^{-1}\right)$

$T=$ the absolute temperature $(\mathrm{K})$

The time function of $V$ can be written as

$$
V(t)=V_{0}-Q_{\mathrm{s}} t
$$

where 
$V_{0}=$ the value of $V$ at $t=0$

$Q_{\mathrm{s}}=$ the 'flux rate' of the piston in the syringe $\left(\mathrm{m}^{3} \mathrm{~s}^{-1}\right)$

The constant $Q_{\mathrm{s}}$ can be calculated from the speed of the piston and the inner crosssectional area of the syringe.

By differentiating Eq. 6 with respect to time and substitution via Eq. 7 one obtains

$$
\left(V_{0}+V_{\mathrm{d}}-Q_{\mathrm{s}} t\right) \frac{\mathrm{d} P}{\mathrm{~d} t}-Q_{\mathrm{s}} P=R T \frac{\mathrm{d} M}{\mathrm{~d} t}
$$
The flow of air out of the space $\left(V+V_{\mathrm{d}}\right)$ is represented by $\frac{\mathrm{d} M}{\mathrm{~d} t}$ and can be related
to $Q_{\mathrm{i}}$ via

$$
R T \frac{\mathrm{d} M}{\mathrm{~d} t}=-R T \gamma Q_{\mathrm{i}}=-P Q_{\mathrm{i}}
$$

where $\gamma\left(\mathrm{mol} \mathrm{m}^{-3}\right)$ is the density of the air, according to $\gamma=M /\left(V+V_{\mathrm{d}}\right)$. By substituting Eq. 2 and Eq. 9 into Eq. 8 and subsequently separating the variables one finds:

$$
\left[P^{2}-2 c P-P_{\mathrm{a}}^{2}\right]^{-1} \mathrm{~d} P=\left[2 c\left\{t-\left(V_{0}+V_{\mathrm{d}}\right) / Q_{\mathrm{s}}\right\}\right]^{-1} \mathrm{~d} t
$$

where

$$
c=\mu L Q_{\mathrm{s}} /(k A)
$$

and $P=P_{\mathrm{i}}$.

During the transient state flow process, $P$ has to be measured at two different times.

Integration of Eq. 10 from $P_{1}$ to $P_{2}$ and from $t=0$ to $t=t$ gives, after writing $t$ explicitly:

$$
t=\left(V_{0}+V_{\mathrm{d}}\right) Q_{\mathrm{s}}^{-1}\left[1-\left\{\frac{\left(P_{2}-c-b\right)\left(P_{1}-c+b\right)}{\left(P_{2}-c+b\right)\left(P_{1}-c-b\right)}\right\}^{c / b}\right]
$$

where

$b=\left(P_{\mathrm{a}}^{2}+c^{2}\right)^{1 / 2}$ and

$P_{1}$ and $P_{2}$ are absolute pressures.

By trial and error, by using a simple computer program, one can find the value of $c$ and subsequently, via Eq. 11, the value of $k$.

The pressure head form of Eq. 12 reads:

$$
t=\left(V_{0}+V_{\mathrm{d}}\right) Q_{\mathrm{s}}^{-1}\left[1-\left\{\frac{\left(h_{2}-C-B\right)\left(h_{1}-C+B\right)}{\left(h_{2}-C+B\right)\left(h_{1}-C-B\right)}\right\}^{C / B}\right]
$$

where 
$C=L Q_{\mathrm{s}} / K A$ and

$B=\left(h_{\mathrm{a}}^{2}+C^{2}\right)^{1 / 2}$

Again, a simple computer program, with the principle of trial and error, produces a value for $C$, from which $K$ can be calculated.

In case $\left(h_{\mathrm{i}}-h_{\mathrm{a}}\right)$ does not rise above $0.2 \mathrm{~m}$, Eq. 13 can be replaced by

$$
t=\left(V_{0}+V_{\mathrm{d}}\right) Q_{\mathrm{s}}^{-1}\left[1-\left\{\frac{h_{1}\left(h_{2}-C-h_{\mathrm{a}}\right)}{h_{2}\left(h_{1}-C-h_{\mathrm{a}}\right)}\right\}^{C /\left(C+h_{\mathrm{a}}\right)}\right]
$$

So far all is still rather simple and straightforward; only $V_{\mathrm{d}}$ still needs to be determined. Problems arise when he pressure sensor does not behave ideally, i.e. when it allows air to escape or changes the value of $V_{\mathrm{d}}$. The magnehelic tends to 'bleed' air from the second port while the pressure is rising. The 'bleeding' stops when the pressure is constant. The bleeding makes the instrument unsuitable for the transient-state $K$ determination. When a water manometer is used, volume changes due to the water movement in the manometer legs must be taken into account in the determination of $V_{\mathrm{d}}$.

\section{Determination of $V_{\mathrm{d}}$}

The value of $V_{\mathrm{d}}$ can be determined by closing the air outlet or using an impermeable 'soil sample' and setting the piston in motion.

According to the ideal gas law

$$
P\left\{V+V_{\mathrm{d}}+\frac{1}{2} \pi r^{2}\left(P-P_{\mathrm{a}}\right) / \varrho_{\mathrm{w}} g\right\}=M R T
$$

should be constant, where $r$ is the inner radius of the legs of the water manometer.

The following example shows how $V_{\mathrm{d}}$ can be determined from a set of observations. After the air outlet is closed, the piston is set in motion at time $t=0$. At that time the pressure in the closed air space is $P_{\mathrm{a}}$, taken to be $1.013 \times 10^{5} \mathrm{~Pa}$.

Observations were made (Table 1) of the values of the manometer pressure $\left(h-h_{\mathrm{a}}\right)=\left(P-P_{\mathrm{a}}\right) / \varrho_{\mathrm{w}} g$ at several points in time. In order to even out the inaccuracies in the observations, a linear regression is carried out (Fig. 2). From the slope of the line, essentially by solving two equations with two unknowns, one can calculate the value of the dead volume, $V_{\mathrm{d}}$, and the value of the constant, $M R T$. For the present example, with

$$
\begin{aligned}
& V_{0}=3.5 \times 10^{-5} \mathrm{~m}^{3} \\
& Q_{\mathrm{s}}=1.09 \times 10^{-7} \mathrm{~m}^{3} \mathrm{~s}^{-1} \text { and } \\
& r \quad=3.5 \times 10^{-3} \mathrm{~m}, \\
& \text { one finds } \\
& V_{\mathrm{d}}=7.7 \times 10^{-5} \mathrm{~m}^{3} \text { and } M R T=11.345 \mathrm{~J} .
\end{aligned}
$$

Table 1 shows that the value of $M R T$ stays reasonably constant during the experiment.

Staying with the simple equipment, including a water manometer, and dealing 


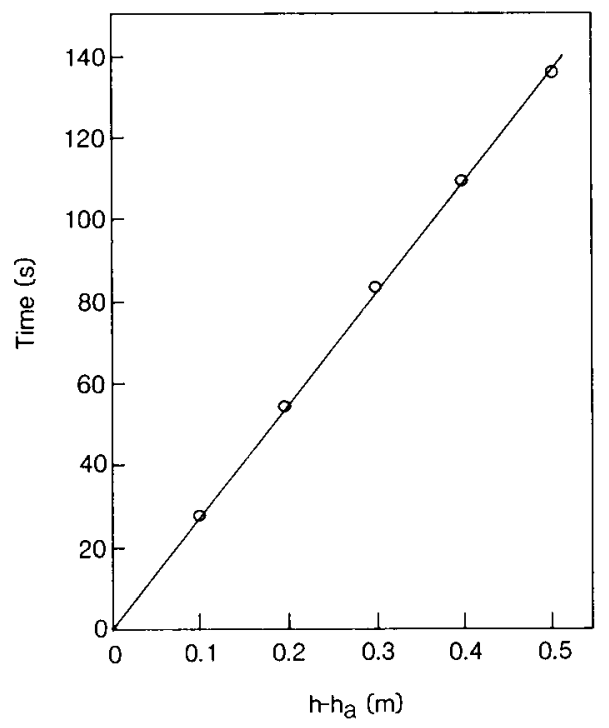

Fig. 2. Relation between $\left(h-h_{\mathrm{a}}\right)$ and time, when the air outlet is closed. $Q_{\mathrm{s}}=1.09 \times 10^{-7}$ $\mathrm{m}^{3} \mathrm{~s}^{-1} ; V_{0}=3.5 \times 10^{-5} \mathrm{~m}^{3}$.

with those cases for which steady state cannot be reached, Eq. 15 now replaces Eq. 6 , and instead of Eq. 8 one now has to find a solution for

$$
\left\{V_{0}+V_{\mathrm{d}}-Q_{\mathrm{s}} t+\pi r^{2}\left(P-P_{\mathrm{a}} / 2\right) / \varrho_{\mathrm{w}} g\right\} \frac{\mathrm{d} P}{\mathrm{~d} t}=Q_{\mathrm{s}} P-Q_{\mathrm{i}} P
$$

After substitution of $Q_{\mathrm{i}}$ according to Eq. 2 separation of variables is no longer possible. However, an approximate solution can be found by writing Eq. 16 in the form

$$
\left[\frac{2 c\left\{t-\left(V_{0}+V_{\mathrm{d}}\right) / Q_{\mathrm{s}}\right\}}{\left(P^{2}-2 c P-P_{\mathrm{a}}^{2}\right)}-\frac{2 c m\left(P-P_{\mathrm{a}} / 2\right)}{\left(P^{2}-2 c P-P_{\mathrm{a}}^{2}\right)}\right] \mathrm{d} P=\mathrm{d} t
$$

where $c$ is as in Eq. 11 and

$$
m=\pi r^{2} / \varrho_{\mathrm{w}} g Q_{\mathrm{s}}
$$

\begin{tabular}{|c|c|c|c|c|c|}
\hline $\begin{array}{l}t^{*} \\
(\mathrm{~s})\end{array}$ & $\begin{array}{l}\left(h-h_{i 1}\right)^{*} \\
(\mathrm{~cm})\end{array}$ & $\begin{array}{l}1 / 2 \pi r^{2}\left(h-h_{\mathrm{a}}\right)^{* *} \\
\left(\mathrm{~cm}^{3}\right)\end{array}$ & $\begin{array}{l}Q_{s} t^{* *} \\
\left(\mathrm{~cm}^{3}\right)\end{array}$ & $\begin{array}{l}P^{* *} \\
\left(10^{5} \mathrm{~Pa}\right)\end{array}$ & $\begin{array}{l}M R T^{* *} \\
(\mathrm{~J})\end{array}$ \\
\hline 0 & 0 & 0 & 0 & 1.0130 & 11.3456 \\
\hline 28 & 10 & 1.9242 & 3.052 & 1.0228 & 11.3400 \\
\hline 54 & 20 & 3.8485 & 5.886 & 1.0326 & 11.3547 \\
\hline 83 & 30 & 5.7727 & 9.047 & 1.0424 & 11.3336 \\
\hline 109 & 40 & 7.6969 & 11.881 & 1.0522 & 11.3444 \\
\hline 135 & 50 & 9.6211 & 14.715 & 1.0620 & 11.3534 \\
\hline
\end{tabular}

Table 1 . Observed and calculated values connected with the determination of $V_{\mathrm{d}}$.

* Observed; ** Calculated. 


\section{P. H. GROENEVELT AND G. G. LEMOINE}

In the absence of the second term in the square brackets, integration of Eq. 17 from $P_{1}$ to $P_{2}$ and from $t=0$ to $t=t$ again yields Eq. 12 .

By subtracting the value of

$$
\int_{P_{1}}^{P_{2}} \frac{2 c m\left(P-P_{\mathrm{a}} / 2\right)}{\left(P^{2}-2 c P-P_{\mathrm{a}}^{2}\right)} \mathrm{d} P
$$

from the solution for $t$ found in Eq. 12, one obtains

$$
\begin{aligned}
& t=\left(V_{0}+V_{\mathrm{d}}\right) Q_{\mathrm{s}}^{-1}\left[1-\left\{\frac{\left(P_{2}-c-b\right)\left(P_{1}-c+b\right)}{\left(P_{2}-c+b\right)\left(P_{1}-c-b\right)}\right\}^{c / b}\right] \\
& -c m\left[\ln \frac{\left(P_{2}^{2}-2 c P_{2}-P_{\mathrm{a}}^{2}\right)}{\left(P_{1}^{2}-2 c P_{1}-P_{\mathrm{a}}^{2}\right)}+\left(\frac{c}{b}-\frac{P_{\mathrm{a}}}{2 b}\right) \ln \left\{\frac{\left(P_{2}-c-b\right)\left(P_{1}-c+b\right)}{\left(P_{2}-c+b\right)\left(P_{1}-c-b\right)}\right\}\right]
\end{aligned}
$$

\section{Verification}

In order to verify the above theory, a sample was chosen that eventually did reach steady state $\left(Q_{\mathrm{i}}=Q_{\mathrm{s}}\right)$, or at least came very close, so that $k$ could be calculated from Eq. 2 and $K$ from Eq. 3.

The last observed value of $\left(h-h_{\mathrm{a}}\right)$ was assumed to be the final constant value. For $Q_{\mathrm{s}} \quad=1.44 \times 10^{-7} \mathrm{~m}^{3} \mathrm{~s}^{-1}$ and

$A=1.9635 \times 10^{-3} \mathrm{~m}^{2}$, the last observed value (see Fig. 3) was

$h-h_{\mathrm{a}}=1.1176 \times 10^{-1} \mathrm{~m}$

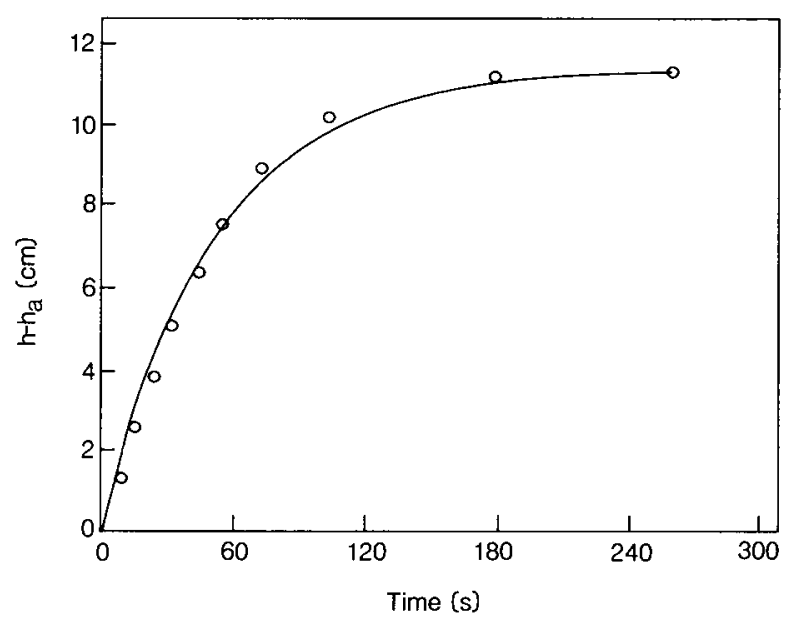

Fig. 3. Measured $\left(h-h_{\mathrm{a}}\right)$ values as a function of time (symbols). $Q_{\mathrm{s}}=1.44 \times 10^{-7} \mathrm{~m}^{3} \mathrm{~s}^{-1} ; V_{0}=2.2 \times 10^{-4}$ $\mathrm{m}^{3}$. The solid line is calculated from Eq. 19. 


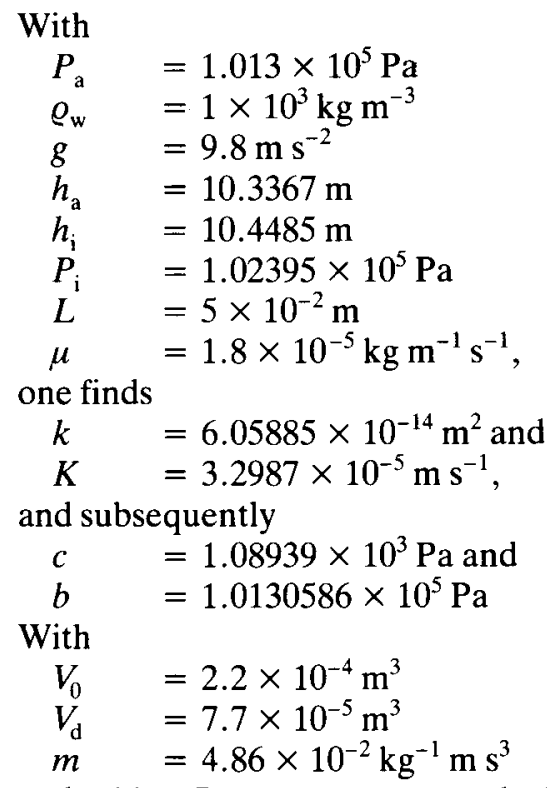

and taking $P_{1}=P_{\text {a }}$, one can calculate from Eq. 19 the time it takes for a certain value of $\left(h-h_{\mathrm{a}}\right)$ to be reached. The solid line in Fig. 3 is calculated from Eq. 19. The symbols represent the observed data points. The calculated curve fits the observed data points quite well.

\section{Conclusion}

Sufficient mathematical tools are available to determine the air permeability accurately with simple instrumentation under transient conditions.

\section{References}

Ball, B. C., 1981a. Modelling of soil pores as tubes using gas permeabilities, gas diffusivities and water release. Journal of Soil Science 32: 465-481.

Ball, B. C., 1981b. Pore characteristics of soils from two cultivation experiments as shown by gas diffusivities and permeabilities and air-filled porosities. Journal of Soil Science 32: 483-498.

Ball, B. C., W. Harris \& J. R. Burford, 1981. A laboratory method to measure gas diffusion and flow in soil and other porous materials. Journal of Soil Science 32: 323-333.

Bolt, G. H. \& R. D. Miller, 1958. Calculation of total and component potentials of water in soil. Transactions American Geophysical Union 39: 917-928.

Buehrer, T. F., 1932. The movement of gases through soil as a criterion of soil structure. Arizona Agricultural Experimental Station, Technical Bulletin $39,57 \mathrm{pp}$.

Corey, A. T., 1986. Air permeability. In: A. Klute (Ed.), Methods of soil analysis, Part 1: Physical and mineralogical methods, 2nd ed., Chap. 48, p. 1121-1136. Monograph No 9, American Society of Agronomy, Madison, WI, USA.

Groenevelt, P. H., B. D. Kay \& C. D. Grant, 1984. Physical assessment of a soil with respect to rooting potential. Geoderma 34: 101-114.

Janse, A. R. P. \& G. H. Bolt, 1960. The determinaton of air permeability of soils. Netherlands Journal of Agricultural Science 8: 124-131. 


\section{P. H. GROENEVELT AND G. G. LEMOINE}

Kirkham, D., 1946. Field methods for determination of air permeability of soil in its undisturbed state. Soil Science Society of America Proceedings 11: 93-99.

Marshall, T. J., 1958. A relation between permeability and size distribution of pores. Journal of Soil Science 9: 1-8.

Perdok, U. D. \& L. M. Hendrikse, 1982. Workability test procedure for arable land. Proceedings 9th Conference of the International Soil Tillage Research Organization (Osijek), p. 511-519.

Reeve, R. C., 1953. A method for determining the stability of soil structure based upon air and water permeability measurements. Soil Science Society of America Proceedings 17: 324-329. 